\title{
Operations and Supply Chain Management: An International Journal - Editorial of Special Issue
}

\author{
Dimitris Folinas \\ Department of Logistics, Alexander Technological Educational Institute of Thessaloniki, Branch of Katerini, Greece, Tel: \\ +30 2351020940, dfolinas@gmail.com. \\ Dimitris Aidonis \\ Department of Logistics, Alexander Technological Educational Institute of Thessaloniki, Branch of Katerini, Greece, Tel: \\ +81466475049, daidonis@auth.gr.
}

\section{Introduction (some facts)}

This special issue has followed up the $1^{\text {st }}$ International Conference on Supply Chains held at October 1-2, 2010, in Katerini, Greece. More than 400 attendances, 100 presenters of research papers, and 6 keynote invited speakers, have participated in the 2-Days Conference that it has been embraced positively by the academic and business community. 80 research papers of them went into the review process ( $20 \mathrm{had}$ to be either rejected at an early stage, because of a lack of relevancy to the conference topics or presented as posters). Then, each of the 80 papers was reviewed by a minimum of two reviewers. In total 160 reviews were collected in a double-blind review process. Finally, 10 papers were accepted and submitted for the final review process in order to be published at the OSCM International Journal. They have been assigned to the Journal's editor in order to ensure that reviewer's comments were interpreted in the most beneficial way.

\section{Content of Special Issue}

The issue is composed of ten (10) articles covering operations-related topics of Supply Chain Management including the following: Supply chain and Logistics operations optimisation (operations such as procurement, inventory management and transportation), Green Logistics, and Innovative Solutions for Efficient Logistics and Supply Chains.

Keramydas et al. in "A Decision-Making Framework for the Optimal Selection of Suppliers" propose a generic methodological framework for the supplier selection and supplier evaluation problem. This framework is constituted by a five phased conceptual decision-making methodology that outlines the whole life cycle of the supplier selection and evaluation processes. Authors also provide a new analytical goal-programming model for the initial selection and the periodic re-evaluation of suppliers in today's globalized environment. This mathematical programming model is based on newly developed and integrated real world supplier quality indices.

Ntio et al. in "Base-Stock Policies for Two and Three Stages Serial Inventory Systems with Stochastic Demand and Replenishments" examined the impact of pure base-stock replenishment policies on performance of multi-echelon supply chain networks. After evaluating cycle inventory, service level, fill rate, work in process and replenishment policy, and studying serial supply chain systems authors explored structures of the transition 
matrices of those systems and they developed computational algorithms to generate them for different values of above systems parameters.

Vidovic et al. in "Optimization of Recyclables Collection Processes" consider the problem of waste materials collection processes, which comprises pickup recyclables from collection points and transferring them to a recycling facility. Therefore, they introduce a planning methodology and a corresponding modelling approach for the optimization of recyclable collection processes. The proposed model considers collection vehicles scheduling, recyclables inventories optimization, and risks minimization.

Papana et al. in "Examination of the Interrelation Among the Price of the Fuel, the Cost of Transport Freight and the Profit Margin", examine the interrelation of the daily price of fuel, the cost of hauling freight from various US geographic locations and the profit margin that various freight haulers may have thereof. Data for the three aforementioned variables are analyzed over a period of 4 years. The conclusions of this work can be helpful in the cost accounting of provided logistic services from a company concerning the prices of oil, aiming to help the company check the costs and the margin of profit.

Chatzipanagioti et al. in "Trade Facilitation and Supply Chain Network Design" provide a quantitative strategic decision support methodology that captures the impact of the variability of order lead time demand on supply chain network design and identifies: (i) the optimal mixture of nearshore / offshore production allocation capacity and (ii) the radius in the hinterland within which a global company can penetrate markets according to the entry point's customs efficiency. Moreover, various "what-if" analyses are conducted in order to explore the sensitivity of the production allocation mixture and the trade-off between travel distance and customs efficiency. The usage of the proposed methodology is demonstrated through its application on an appropriately simplistic problem, while obtained managerial insights are discussed.

Cuc et al. in "Environmental Sustainability through Clothing Recycling" examine the process of achieving environmental sustainability through recycling of textile wastes. Specifically, the paper proposes a modeling framework which makes trade off between costs of reverse network for textiles waste establishing and operating, and its effects on the virgin materials consumption, land use reduction, employment increase, and resold wearable textiles earnings

"Costing Logistics Services", by Hatzis et al., presents and evaluates the costing systems that the 3PL's companies have used. It is based on a survey that is focused on logistics providers in Greece. This survey aimed at first to identify the adopted costing system, to assess its significance for both the provision of services and the designing - redesigning of services' portfolio, to estimate the degree of satisfaction by top managers, and to recognize the problems regarding the existing costing system such as the non-value added logistics services.

Lacroix et al. discuss in "City of London 20072010 Green Public e-Procurement Project-Results and Perspectives" how the 2007-2010 Green Public eprocurement project was structured; the goals, accountabilities, results of the procurement portfolioanalysis, the significance of business transformation with e-procurement, the local performance Indicators which were used and the initial spend results of the project. Authors argue that the examined can be a best practice for a potential application in Balkan countries.

Kazantzi et al. in "Simulating the Effects of Risk Occurrences on a Hazardous Material Transportation Model" explore the effects of different risk incidents on a Transportation Model developed for HazMat (Hazardous Materials) shipments. The paper elucidates the effects of occurrence probabilities of the different risk events on the transportation model featuring total transportation cost. In order to examine the impact of the occurrence possibilities of different risk events on the transportation model, appropriate parameterized simulation work is carried out, resulting in identifying release probability zones and safe network configurations that correspond to certain low-risk levels and degrees of risk-related uncertainties.

Chatzoudes et al. in "The Impact of $360^{\circ}$ Supply Chain Integration on Operational and Business Performance" aim to explore supply chain integration on a 360 degree radius, thus, suggesting a Conceptual Framework that accounts for all aspects. The examination of the proposed Conceptual Framework was made with the use of a structure questionnaire. The questionnaire was distributed to a group of Greek manufacturing companies. The empirical data were 
analyzed using the "Structural Equation Modelling" technique. Results offer both theoretical and empirical evidence.

\section{Conclusion}

The papers received to this call for contributions gave a clear sign that supply chain management will still remain to be a hot topic of research in the forthcoming years. Specifically, supply chain optimisation has been a topic of significant academic interest in the operational research discipline for the last decades. There are many issues that are still not fully resolved but, the authors of the above papers have made their contributions to bring this ultimate goal one step closer.

\section{Acknowledgements}

Special thanks to our reviewers who have provided relevant and detailed comments to the authors of all papers submitted and helped us in the selection process: Dimitris Triantafyllou, Dimitris Folinas, Ioannis Manikas, and Dimitris Aidonis.

\section{Kindest regards,}

\section{Professor Dimitris Triantafillou}

The President of the Organizing Committee of the $1^{\text {st }}$ ICSC Conference. 